AJHSE Vol: 1 (2): 101-112, 2020

Article Ref. No.: AJHSE0102010

Accepted Date: December 02, 2020 (C) 2020. CC License 4.0

www.ajhse.org

African Journal of Health, Safety and Environment

An official publication of the

Applied Environmental Bioscience and Public Health Research Group

University of Benin, Benin City, Nigeria

Open Access | Bi-annual | Peer-reviewed | International ISSN (Online): 2695-1819 | ISSN (Print): 2695-2386

\title{
ASSESSING THE UTILITY OF A CYTOKINE IN THE DIAGNOSIS OF CERVICAL INTRAEPITHELIAL NEOPLASM AMONG WOMEN IN BENIN CITY, NIGERIA
}

\author{
${ }^{* 1,2,3}$ Atoe, K., ${ }^{4}$ Ehimigbai, R. O. A., ${ }^{5}$ Ayinbuomwan, E. and ${ }^{5}$ Onovughakpo-Sakpa, O. E.
}

\author{
${ }^{*}$ Department of Chemical Pathology, Edo University, Iyamho, Edo State, Nigeria \\ ${ }^{2}$ Applied Environmental Bioscience and Public Research Group, University of Benin, Benin City, Nigeria \\ ${ }^{3}$ Phytomedicine and Drug Discovery Research Group, Dept. of Plant Biology and Biotechnol., University of Benin, Benin City, Nigeria \\ ${ }^{4}$ Dep artment of Anatomy, University of Benin, Benin City, Nigeria \\ ${ }^{5}$ Department of Chemical Pathology, University of Benin, Benin City, Nigeria \\ *Corresponding Author's E-mail: atoe.kenneth@edouniversity.edu.ng
}

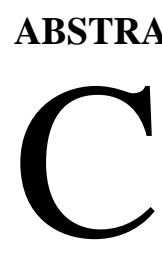

ervical cancer has been recognized as the fourth commonest cancer worldwide with $70 \%$ of deaths from cases occurring from developing countries. The mortality rate among women in Nigeria can be drastically reduced by early specific diagnosis of premalignant lesions. Although Cytokines are not routinely used as diagnostic markers for cervical cancer, this study investigated the strength of Granulocyte Monocyte Colony Stimulating growth Factor (GM-CSF) as an indicator in the prediction of Cervical Intraepithelial Neoplasm (CIN). The study was carried out at the Department of Obstetrics and Gynaecology, University of Benin Teaching Hospital Benin City and Department of Chemical Pathology, Edo University Iyamho, Edo state Nigeria, between August, 2017 and January 2019. It was a cross-sectional prospective study. A total of 197 female participants were recruited for this study. Based on histological diagnosis they were grouped as; Negative, CIN 1, CIN 2 and CIN 3. Venous blood was obtained from participants and serum GM-CSF levels were determined using standardized laboratory methods. The results showed a statistically significant elevation of serum GM-CSF in participants with CIN lesions $(56.27 \pm 1.21 \mathrm{ng} / \mathrm{ml})$ compared to those without $(33.43 \pm 3.03 \mathrm{ng} / \mathrm{ml})$. The study also suggests a $56.3 \%$ sensitivity and a 95.3\% specificity of GM-CSF marker to CIN with an Area under the Curve (AUC) of 0 .907, p<0.001 from the Receivers Operator Curve (ROC). This research suggests the use of GM-CSF as a good marker for screening of those at risk of cervical cancer because of its high prospect to reduce the incidence of false positives. However, because of the low sensitivity, it is recommended that GM-CSF be used as a CIN diagnostic tool in combination with the standard Pap smear test.

Keywords: Benin City, Cervix, Cancer, Diagnosis, GM-CSF, Neoplasia, Smoking, Metabolic medicine

LICENSE: This article by African Journal of Health, Safety and Environment (AJHSE)is licensed and published under the Creative Commons Attribution License 4.0 International License, which permits unrestricted use, distribution, and reproduction in any medium, provided this article is duly cited.

COPYRIGHT: The Author(s) completely retain the copyright of this published article.

OPEN ACCESS: The Author(s) approves that this article remains permanently online in the open access (OA) mode. 


\section{INTRODUCTION}

The prevalence of invasive cervical cancer in Sub-Sahara Africa is on the increase and it is the most common cancer in women globally (Pisani et al., 1999). The rising concern and disturbance about cervical cancer is that all women are possibly at risk of developing cervical cancer at some point in their lifetime (Lawicki et al., 2008). Cervical cancer is a type of tumor that affects the lowest part of the uterus. A woman is at risk once she turns fifteen. Approximately $80 \%$ of cases occur in developing countries (Parkin et al., 2005). It is one of the leading causes of death among the female population in Nigeria. In 2007, it was stated that 36.59 million women aged $\geq 15$ years in Nigeria are at risk of developing cervical cancer (Ahmed et al., 2013). Luckily, this cancer is avertable by screening for premalignant lesions. Sadly, it is seldom provided and exploited (Gorelik et al., 2005).

In developing countries, there is a dearth of active screening tools for premalignant lesions. In Nigeria, no clinically substantial decrease in the incidence of cervical cancer has occurred during the past four decades (Mohammed et al., 2006). In advanced countries, by contrast, there has been a major drop in cervical cancer deaths after the institution of extensive cytological testing (Kalliala et al., 2005). Diagnostic testing tools for ascertaining cancer ranges from classical methods (Papanicolaou test known as Pap smear) to modern methods. The modern method includes the use of cytokines called hematopoietic growth factors (HGFs). The levels of HGF are used as indicators of possible cancer cells (Averette and Janicek, 2001). The increasing or declining value of indicator levels in prevalent malignancies predict progression or remission of the condition (Lawicki et al., 2012).

Investigations to explore the diagnostic potential of hematopoietic growth factors (HGFs) such as (interleukin (IL), interferon (IFN), granulocyte-colony stimulating factor (G-CSF), granulocyte-macrophage-colony stimulating factor (GM-CSF), macrophage-colony stimulating factor (M-CSF), and tumor necrosis factor (TNF) as markers for early diagnosis of Cervical intra epithelial neoplasia (CIN) is critical in the mitigation of this deadly genital cancer. Cytokines play a key role in the regulation of cells of the immune system and also have been implicated in the pathogenesis of malignant diseases (Ahn et al., 2005). GM-CSF is a byproduct of the metabolism of tumor cells. This biomarker is the most widely used serum marker for breast cancer. The production of GM-CSF has been demonstrated in a number of non-hematologic malignancies including tumors of the cervix (Watanabe et al., 2000). The use of GMCSF in this study was also due to the hormonal interaction between the cervix and breast of a woman in the reproduction age bracket. This research examined the capacity of GM-CSF as an early indicator in the diagnosis of cervical intra epithelial neoplasia (CIN).

\section{MATERIALS AND METHODS PARTICIPANTS}

A total of 197 participants were recruited for this study at the Urogynaecology and Gynae-oncology Unit of the Department of Obstetrics and Gynaecology, University of Benin Teaching Hospital (UBTH) from August 2017 to January 2019. Informed consent was obtained from participants during study. 


\section{METHODOLOGY}

The biochemical analysis of the research participants was done at the Metabolic Research Unit of the Department of Chemical Pathology, Edo University Iyamho, Edo state, Nigeria. Cases included patients with histological diagnosis of cervical intraepithelial neoplasm and abnormal Pap smear referred from Gynaecology Clinic, General Practice

Clinic, Community Development Clinic in UBTH and also referrals for Colposcopy from private hospitals in Benin City. Control participants were selected from the Gynaecology clinic of UBTH and were patients with normal Colposcopy who matched the case for age and parity. Socio-demographic characteristics of participants in the study consisted of information relating to age, unsuccessful conception, marriage type and smoking habit, which were possible risk factors for CIN.

Venipuncture was done for all the participants for collection of blood sample for biochemical analysis. $5 \mathrm{ml}$ of blood samples was collected into a plain tube, allowed to clot and retract, thereafter centrifuged at $2000 \mathrm{rpm}$ for 15 minutes. The serum was collected with Pasteur pipette into a plain tube and then stored at about $-4{ }^{\circ} \mathrm{C}$ until the biochemical analysis was carried out. The biochemical analysis of the granulocyte monocyte colony stimulating growth factor (GM-CSF) was carried out using the enzyme linked Immunosorbent Assay (ELISA) method.

\section{DATA ANALYSIS}

Data collected were analyzed using SPSS version 20. Results were presented using Tables, Plates and graphs. Quantitative variables were expressed as mean \pm standard deviation. Pearson's Coefficient of Correlation was used to correlate occurrence of GM-CSF with other risk factors associated with CIN in the participants. Receiver Operator Characteristic (ROC) curves was used for the best-fitting model, whereas Area Under Curve (AUC) was used for prediction of GM-CSF. One-way analysis of variance was used to analyze GM-CSF values for the various CIN statuses.

\section{RESULTS AND DISCUSSIONS}

The socio-demographic information of the study participants showed that there was a total of 53 participants that were negative for CIN lesions, compared to 144 that had CIN lesion based on histological diagnosis (Table 1). The participants were also grouped according to age, with most of the participants in both control and CIN groups belonging to the $51-60 \mathrm{yrs}$ age category. More than $30 \%$ of the participants with a positive CIN histological result were smokers, compared to $13.2 \%$ in the control. This perhaps may point to smoking as being a risk factor for CIN. Although there were a significant number of smokers within those who were positive for CIN (see Table 1), the distribution of the GM-CSF results in the smokers did not significantly differ from non-smokers. Mean GM-CSF in the smoking group was $47.93 \mathrm{ng} / \mathrm{ml}$, whereas the value was $50.93 \mathrm{ng} / \mathrm{ml}$ within the non-smoking group (Fig. 1).

Several human non-hematopoietic cancers have been shown to express increased levels of GM-CSF (Ohwada et al., 2006). CIN status obtained from Pap smear results were in three stages; early stage, intermediate and full-blown stage. They were represented as CIN 1, 2 and 3 respectively. Fifty-three women were diagnosed negative to CIN. Those with CIN lesions had a mean GM-CSF of $56.27 \pm 1.21 \mathrm{ng} / \mathrm{ml}$ which was significantly higher than those of the control group (33.43 $\pm 3.03 \mathrm{ng} / \mathrm{ml}$ ) (Table 2). This is similar to the findings of Ławicki et al. $(2008,2012)$ who reported 
that in a group of cervical cancer patients, the plasma levels of GM-CSF, G-CSF and M-CSF were significantly different compared to the healthy controls. The result in Figure 2 defined the Receiver Operator Characteristic (ROC) curves for standard GM-CSF benchmark and identified the best-fitting model of GM-CSF at 55.3ng/ml. This place the diagnostic strength of the marker at stage 2 of the CIN lesion. The ROC curve is a resourceful way to appraise the predictive capacity of a parameter with continuous values and is used to evaluate the discriminating power of a diagnostic test (Liu et al., 2005). In the correlation model presented in Table 3, GM-CSF examined with other risk factors associated with CIN, had significant positive correlation at 0.01 and its resulting ROC curve had high AUC value of (>0.907). However, it was found to be a low sensitive predictor of CIN. This observation from the present study is similar to the report by Lyon and colleagues (Lyon et al., 2008) in a study where multiple cytokines were used in the diagnosis of breast cancer. The bulk cytokine model comprising of GM-CSF performed less than the others investigated in terms of sensitivity to the disease.

The diagnostic efficiency of tumor markers like GM-CSF depends on variety of factors such as sensitivity, specificity, positive predictive value (PPV) and negative predictive value (NPV) (Leek and Harris, 2002). The sensitivity of tumor marker is the probability that the test results will be positive if a tumor is present. Based on the result from the coordinates of the ROC curve, GM-CSF marker was not sensitive to CIN at stage 1 and may not be useful as an early marker (Table 4, Plate 1). Plates 2, 3, and 4 also shows sections of dysplastic squamous epithelial cells involving the lower two-thirds, thickness of the ecto cervix, as well as normal squamous epithelial cells lining the ectocervix.

The findings in Table 5 and 6 compares the diagnostic strength of GM-CSF as a marker for predicting CA cervix against histology. GM-CSF confirms negative to CIN as predicted by histology at $92.5 \%$. The Negative Predictive Value (NPV) value was $94.1 \%$ (Table 5). NPV describes the probability that the disease is not actually present if the test result is negative (Liu et al., 2005). This shows the capacity of the biomarker as a high specific predictor of healthy patients. Specificity of tumor marker as a screening parameter indicates whether it may be used for describing the percentage of healthy individuals with negative test results (Campbell, 1994).

It can be deduced from this research that GM-CSF is a low sensitive biomarker to CIN but highly specific in detecting patients without the disease.

The capacity for GM-CSF for diagnosis of CIN was compared with histology (Table 7). Using histology of the pap smear obtained from a total of 197 participants, histology was able to identify 144 participants to be positive for CIN, whereas 53 were negative. However, the use of GM-CSF, based on the cut-off score obtained (see Figure 2, Table 4) divided the participants into 122 individuals with a negative premalignant lesion and 85 participants with positive CIN pap smear. This indicated that GM-CSF was only able to identify $43.15 \%$ of the participants to be positive for CIN lesion, compared to the $73.10 \%$ identified by pap smear. GM-CSF is therefore not a good marker based on the results of histology. 


\section{CONCLUSION}

Theoretically, an ideal biochemical marker should be extremely sensitive and specific, have low false positives, high positive and negative predictive value, most essentially should be $100 \%$ accurate in distinguishing between healthy persons and patients with premalignant conditions. This research finds GM-CSF as an ideal marker for arbitrary population screening because of its high prospect to drastically reduce the incidence of false positives. However, it is recommended that GM-CSF be used as a CIN diagnostic tool in combination with the standard Pap smear test.

Table 1: Socio-demographic characteristics of participants in the study

\begin{tabular}{|c|c|c|c|c|c|c|c|c|}
\hline \multirow[t]{2}{*}{ Parameters } & & \multicolumn{2}{|c|}{$\begin{array}{l}\text { CIN group } \\
(n=144)\end{array}$} & \multicolumn{2}{|c|}{$\begin{array}{l}\text { Control group } \\
(\mathrm{n}=53)\end{array}$} & \multirow[t]{2}{*}{ df } & \multirow[t]{2}{*}{$\overline{X^{2}}$} & \multirow[t]{2}{*}{ p-value } \\
\hline & & (n) & $(\%)$ & (n) & $(\%)$ & & & \\
\hline \multirow[t]{4}{*}{ CIN.Staus } & Negative & 0 & 0.0 & 53 & 26.9 & 3.0 & 0.463 & 0.925 \\
\hline & Level 1 & 45 & 22.8 & 0 & 0.0 & & & \\
\hline & Level 2 & 49 & 24.9 & 0 & 0.0 & & & \\
\hline & Level 3 & 50 & 25.4 & 0 & 0.0 & & & \\
\hline \multirow[t]{5}{*}{ Age group } & $31-40 \mathrm{yrs}$ & 17 & 11.8 & 15 & 28.3 & 4.0 & 5.784 & 0.216 \\
\hline & $41-50 \mathrm{yrs}$ & 32 & 22.2 & 10 & 18.9 & & & \\
\hline & $51-60 \mathrm{yrs}$ & 56 & 38.9 & 20 & 37.7 & & & \\
\hline & $61-70 \mathrm{yrs}$ & 10 & 6.9 & 8 & 15.1 & & & \\
\hline & $>70 \mathrm{yrs}$ & 29 & 20.1 & 0 & 0.0 & & & \\
\hline \multirow[t]{3}{*}{ Educational level } & Primary Edu. & 58 & 40.3 & 5 & 9.4 & 2.0 & 2 & 0.368 \\
\hline & Secondary Edu. & 16 & 11.1 & 26 & 49.1 & & & \\
\hline & Tertiary Edu. & 70 & 48.6 & 22 & 41.5 & & & \\
\hline \multirow[t]{9}{*}{ Parity } & 1.00 & 0 & 0.0 & 9 & 17.0 & 8.0 & 11.501 & 0.175 \\
\hline & 2.00 & 6 & 4.2 & 0 & 0.0 & & & \\
\hline & 3.00 & 24 & 16.7 & 11 & 20.8 & & & \\
\hline & 4.00 & 38 & 26.4 & 17 & 32.1 & & & \\
\hline & 5.00 & 32 & 22.2 & 6 & 11.3 & & & \\
\hline & 6.00 & 19 & 13.2 & 8 & 15.1 & & & \\
\hline & 7.00 & 0 & 0.0 & 2 & 3.8 & & & \\
\hline & 8.00 & 22 & 15.3 & 0 & 0.0 & & & \\
\hline & 11.00 & 3 & 2.1 & 0 & 0.0 & & & \\
\hline \multirow{4}{*}{$\begin{array}{l}\text { Unsuccessful } \\
\text { conception }\end{array}$} & None & 142 & 98.6 & 49 & 92.5 & 3.0 & 4.386 & 0.223 \\
\hline & Once & 0 & 0.0 & 4 & 7.5 & & & \\
\hline & Twice & 1 & 0.7 & 0 & .0 & & & \\
\hline & More than twice & 1 & 0.7 & 0 & .0 & & & \\
\hline \multirow[t]{2}{*}{ Marriage type } & Monogamy & 127 & 88.2 & 37 & 69.8 & 1.0 & 2.4 & 0.121 \\
\hline & Polygamy & 17 & 11.8 & 16 & 30.2 & & & \\
\hline \multirow{2}{*}{ Smoking habit } & Smokers & 46 & 31.9 & 7 & 13.2 & 1.0 & 2.4 & 0.121 \\
\hline & Non-Smokers & 98 & 68.1 & 46 & 86.8 & & & \\
\hline History of usage of & No history & 66 & 45.8 & 24 & 45.3 & 4.0 & 5.564 & 0.234 \\
\hline \multirow[t]{4}{*}{$\mathrm{OCP}$} & $<1 \mathrm{yr}$ & 68 & 47.2 & 9 & 17.0 & & & \\
\hline & $1-3 \mathrm{yrs}$ & 4 & 2.8 & 5 & 9.4 & & & \\
\hline & $4-6 \mathrm{yrs}$ & 0 & 0.0 & 12 & 22.6 & & & \\
\hline & $>6 \mathrm{yrs}$ & 6 & 4.2 & 3 & 5.7 & & & \\
\hline
\end{tabular}


Table 2: GM-CSF values for various CIN status.

\begin{tabular}{|c|c|c|c|c|c|c|c|}
\hline \multirow{2}{*}{$\begin{array}{l}\text { CIN } \\
\text { Status }\end{array}$} & \multirow[b]{2}{*}{ (n) } & \multirow{2}{*}{$\begin{array}{l}\text { Mean } \pm \text { SEM } \\
(\mathrm{ng} / \mathrm{ml})\end{array}$} & \multicolumn{3}{|c|}{$95 \% \mathrm{CI}$} & \multicolumn{2}{|l|}{ ANOVA } \\
\hline & & & Mean CIN & Lower & Upper & $\begin{array}{l}\text { F- } \\
\text { statistic }\end{array}$ & p-value \\
\hline Negative & 53 & $33.43^{c} \pm 3.03$ & - & 27.34 & 39.51 & 47.94 & $<0.001$ \\
\hline Stage 1 & 45 & $47.89^{b} \pm 1.71$ & & 44.46 & 51.32 & & \\
\hline Stage 2 & 49 & $51.23^{b} \pm 1.57$ & $56.27 \pm 1.21$ & 48.08 & 54.38 & & \\
\hline Stage 3 & 50 & $68.74^{\mathrm{a}} \pm 1.64$ & & 65.44 & 72.04 & & \\
\hline
\end{tabular}

Means with similar alphabetic superscripts on the same column do not differ from each other ( $p>0.05)$.

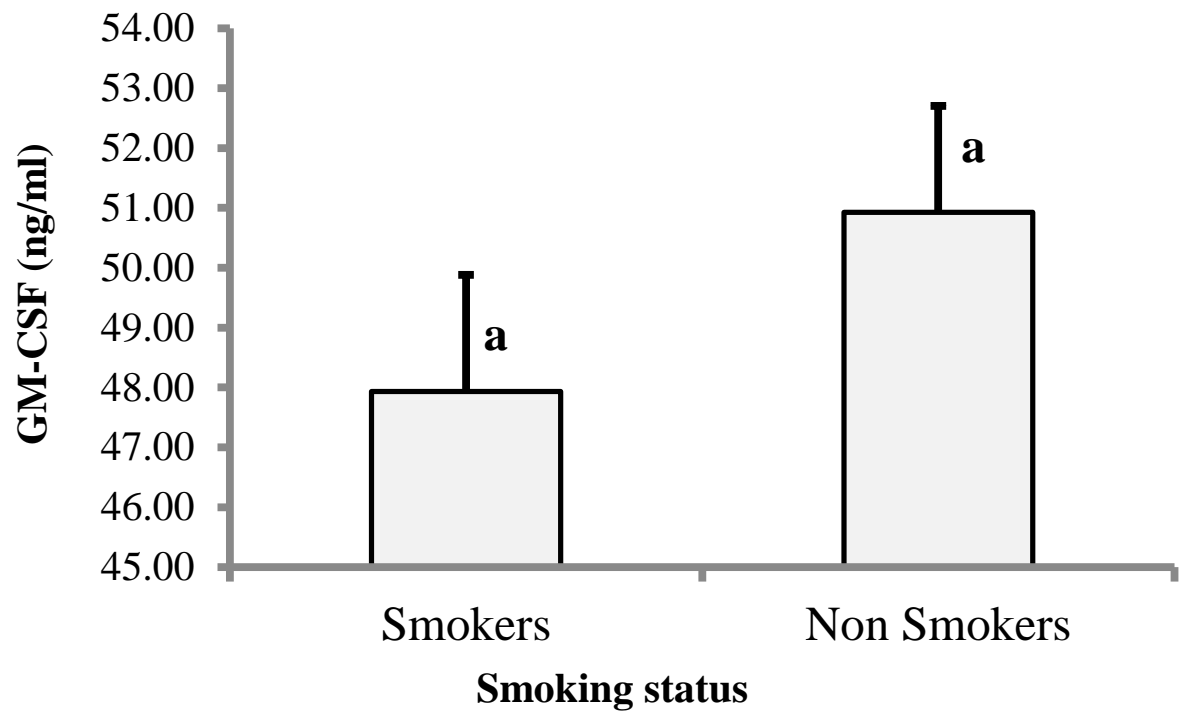

Figure 1: Distribution of GM-CSF values of the study participants based on history of smoking

Table 3: Correlating GM-CSF with other risk factors associated with CIN.

\begin{tabular}{lcc}
\hline Parameters & CIN.Staus & GM-CSF \\
\cline { 2 - 3 } CIN.Staus & 1 & $0.637^{* *}$ \\
Age & $0.336^{* *}$ & 0.075 \\
Age group & $0.259^{* *}$ & 0.062 \\
Pariity & $0.204^{* *}$ & -0.066 \\
Unsuccessful Conception & -0.086 & -0.058 \\
Smoking & 0.018 & 0.068 \\
History of OCP & -0.035 & 0.055 \\
GM-CSF & $0.637^{* *}$ & 1 \\
\hline
\end{tabular}

Values presented are Pearson's Coefficient of Correlation

*. Correlation is significant at the 0.05 level (2-tailed).

**. Correlation is significant at the 0.01 level (2-tailed). 


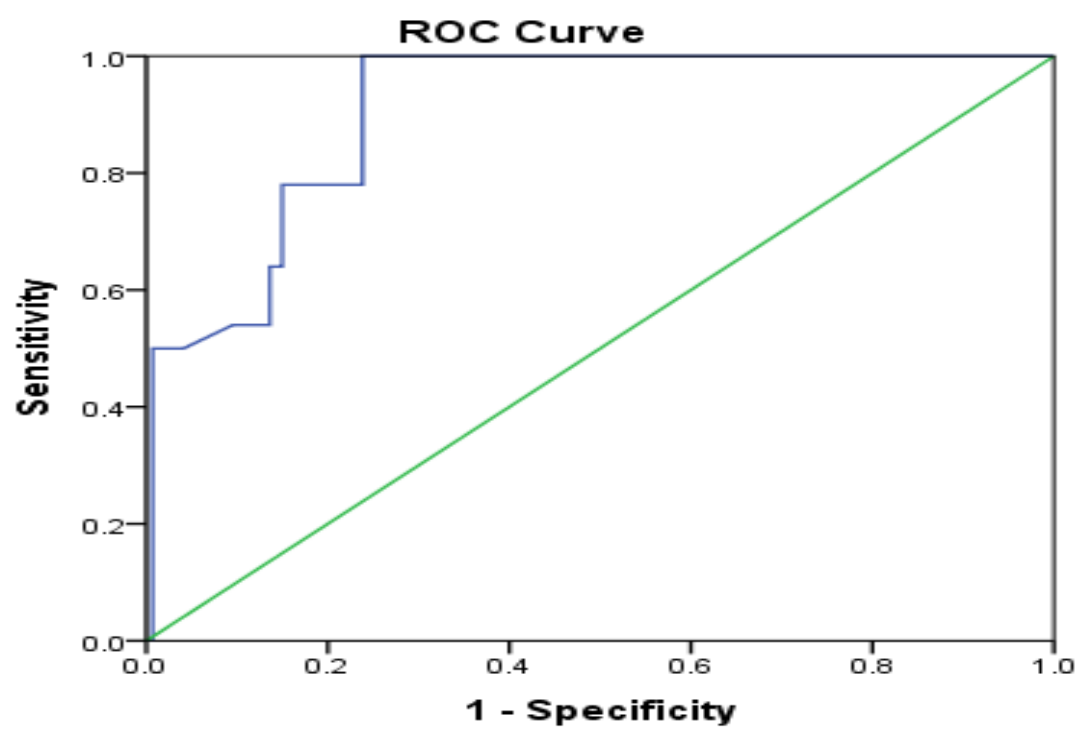

Figure 2: ROC for diagnostic statistical presentation of GM-CSF as a possible biomarker for CA cervix (AUC $=0.907, \mathrm{p}<0.001)$.

Table 4: Coordinates of the receiver operator characteristic (ROC) Curve

\begin{tabular}{ccc}
\hline Positive if Greater Than or Equal To $^{\mathbf{a}}$ & Sensitivity & 1 - Specificity \\
\hline 10.00 & 1.00 & 1.00 \\
36.35 & 1.00 & 0.71 \\
38.20 & 1.00 & 0.64 \\
41.00 & 1.00 & 0.60 \\
42.15 & 1.00 & 0.58 \\
46.10 & 1.00 & 0.39 \\
47.60 & 1.00 & 0.35 \\
49.35 & 1.00 & 0.32 \\
51.15 & 1.00 & 0.29 \\
52.80 & 1.00 & 0.27 \\
53.50 & 1.00 & 0.26 \\
54.50 & 1.00 & 0.25 \\
$\mathbf{5 5 . 3 0 * * *}$ & $\mathbf{1 . 0 0}$ & $\mathbf{0 . 2 4}$ \\
55.65 & 0.78 & 0.24 \\
82.50 & 0.14 & 0.01 \\
87.50 & 0.12 & 0.01 \\
123.80 & 0.00 & 0.01 \\
160.60 & 0.00 & 0.00 \\
\hline
\end{tabular}

The test result variable(s): GMCSF has at least one tie between the positive actual state group and the negative actual state group.

a. The smallest cutoff value is the minimum observed test value minus 1 , and the largest cutoff value is the maximum observed test value plus 1 . All the other cutoff values are the averages of two consecutive ordered observed test values. 
Table 5: $2 \times 2$ contingency for CA cervix prediction by GM-CSF vs. histology

\begin{tabular}{llcccc}
\hline \multirow{2}{*}{ Parameters } & & \multicolumn{2}{c}{ By GM-CSF } & \\
\cline { 3 - 4 } & & & Normal & CIN & Total \\
\hline Histology & Normal & Count & 49 & 4 & 53 \\
& & \% within Histology & 92.5 & 7.5 & 100.0 \\
& CIN & Count & 63 & 81 & 144 \\
& & \% within Histology & 43.8 & 56.3 & 100.0 \\
\hline Total & & Count & 112 & 112 & 85 \\
& & \% within Histology & 56.9 & 56.9 & 43.1 \\
\hline
\end{tabular}

Table 6: Sensitivity and specificity of GM-CSF as a marker for predicting CA cervix

\begin{tabular}{lrc}
\hline Parameters & \multicolumn{2}{c}{-value } \\
\cline { 2 - 3 } Sensitivity & $56.30 \%$ & - \\
Specificity & $95.3 \%$ & - \\
PPV & 95.3 & - \\
NPV & 43.8 & - \\
Prevalence of disease & 43.1 & - \\
Pearson Chi-Square & 37.46 & $<0.001$ \\
Likelihood Ratio & 43.655 & $<0.001$ \\
Linear-by-Linear Association & 37.271 & $<0.001$ \\
Cramer's V & 0.436 & $<0.001$ \\
Odds Ratio & 15.750 & - \\
Relative risk & 2.113 & - \\
\hline
\end{tabular}

Table 7: Prediction capacity of GM-CSF compared to histology

\begin{tabular}{lcccc}
\hline Parameters & Pormal & $\begin{array}{l}\text { Positive } \\
\text { for } \\
\text { CIN }\end{array}$ & $\begin{array}{l}\text { Percentage } \\
\text { CIN } \\
\text { identified }\end{array}$ & Total \\
\hline Separation of patients by histology & 53 & 144 & 73.10 & 197 \\
Separation of patients by GM-CSF & 122 & 85 & 43.15 & 197 \\
\hline
\end{tabular}




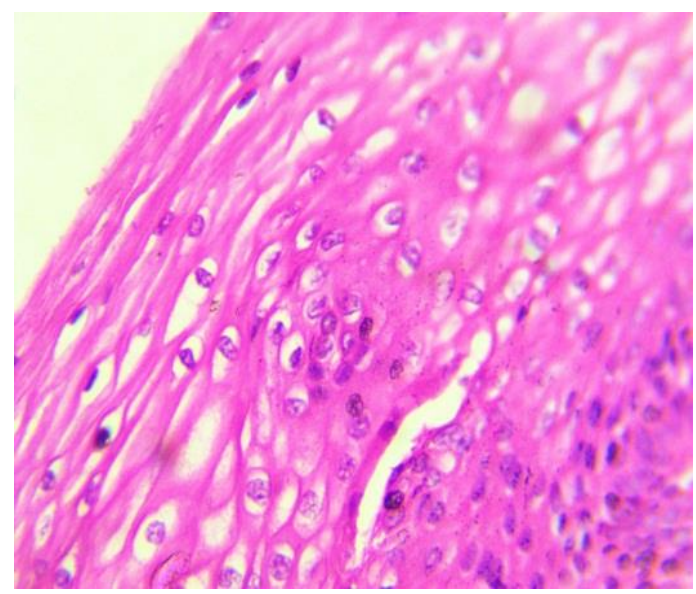

Plate 1: CIN-1 x40. Sections showing dysplastic squamous epithelial cells involving the lower third of the ecto cervix.

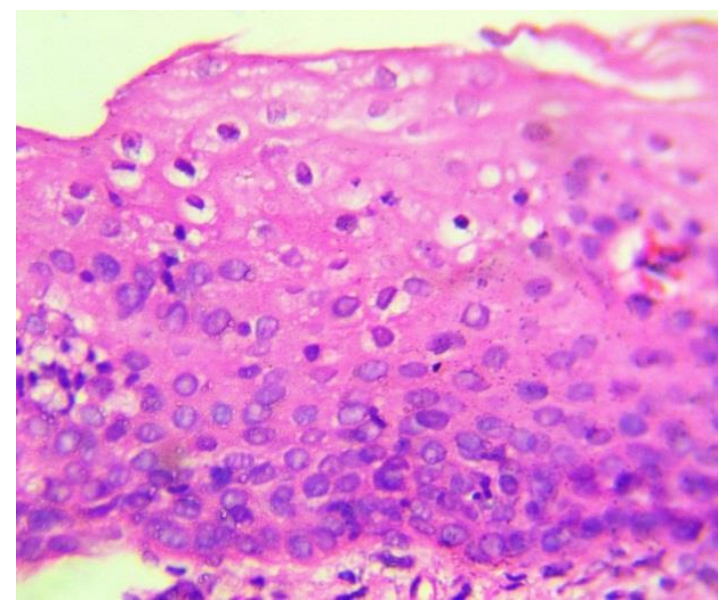

Plate 2: CIN-2 x40. Sections showing dysplastic squamous epithelial cells involving the lower two-thirds of the ecto cervix.

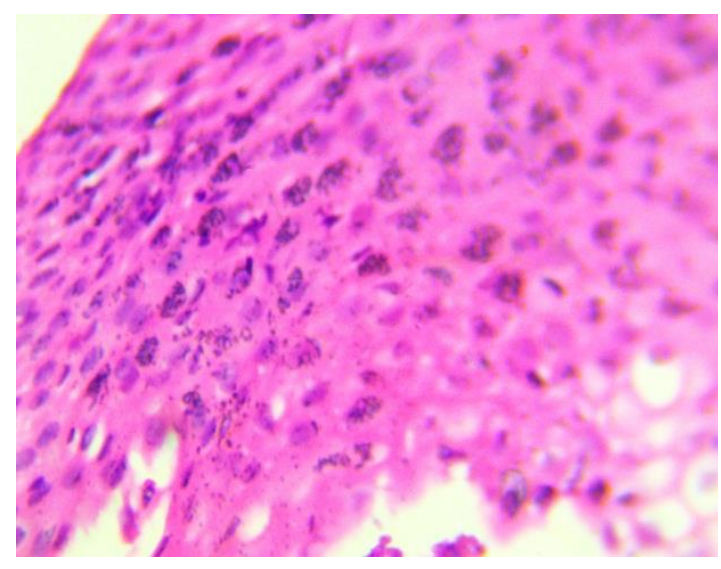

Plate 3: CIN-3 x40. Sections showing dysplastic squamous epithelial cells involving the full thickness of the ecto cervix. 


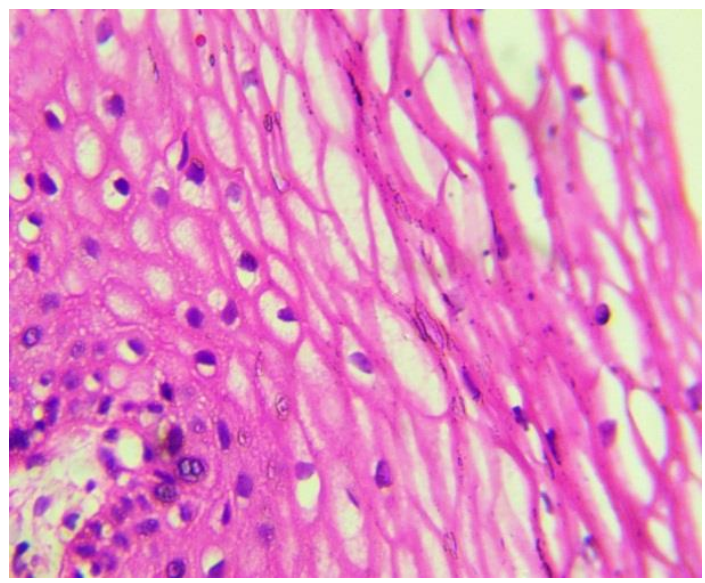

Plate 4: Normal x40. Sections showing normal squamous epithelial cells lining the ectocervix. 


\section{REFERENCES}

Ahmed, S.A., Sabitu, K., Idris, S.H., Ahmed, R. (2013) Knowledge, attitude and practice of cervical cancer screening among market women in Zaria, Nigeria. Nigerian Medical Journal, 54: 316-9

Ahn, H.J., Park, Y.H., Chang, Y.H et al. (2005). A case of uterine cervical cancer presenting with granulocytosis. Korean Journal Internal Medicine, 20: 247-250.

Averette, H.E, Janicek, M.F. (2001). Cervical cancer prevention, diagnosis and therapeutics. $C A$ : A Cancer Journal for Clinicians, 51: 92-114.

Campbell, G. (1994). Advances in statistical methodology for the evaluation of diagnostic and laboratory tests. Statistics in Medicine 13(5-7) : 499-508.

Gorelik, E., Landsittel, D.P., Marrangoni, A.M., Modugno, F., Velikokhatnaya, L., Winans, M.T., et al. (2005). Multiplexed immunobead-based cytokine profiling for early detection of ovarian cancer. Cancer Epidemiology, Biomarkers \& Prevention, 14(4) : 981-987.

Kalliala, I., Anttila, A., Pukkala, E., Nieminen, P. (2005). Risk of cervical and other cancers after treatment of cervical intraepithelial neoplasia: retrospective cohort study BMJ 2005;331: 1183 doi: https: //doi.org/10.1136/bmj.38663.459039.7C

Lawicki, S., Będkowska, G.E., Gacuta-Szumarska, E., Knavol, P., Szmitkowski, M. (2008). The plasma levels and diagnostics utility of stem cell factor (SCF) and macrophage-colony stimulating factor (M-CSF) in cervical cancer patients. Polish Medical Journal, 25: 38-42.

Leek, R., Harris, A. (2002). Tumor-associated macrophages in breast cancer. Journal of Mammary Gland Biology and Neoplasia,7(2): 177-189.

Liu, H., Li, G., Cumberland, W.G., Wu, T. (2005). Testing statistical significance of the area under a receiving operating characteristics curve for repeated measures design with bootstring. Journal of Data Science, 3(3): 257-278.

Lyon, D.E, McCain, N.L, Walter, J., Schubert, C. (2008). Cytokine Comparisons Between Women with Breast Cancer and Women with a Negative Breast Biopsy. Nursing Research, 57(1): 51-58.

Mohammed, A., Ahmed, S.A., Oluwole, O.P., Avidime, S. (2006). Malignant tumours of the female genital tract in Zaria, Nigeria: Analysis of 513 cases. Annals of African Medicine, 93-96.

Ohwada, M., Wada, T., Saga, Y. et al. (2006). C-kit overexpression in neuroendocrine small cell carcinoma of the uterine cervix. European Journal of Gynaecologiocal Oncology. 27: 5355. 
Parkin, D.M., Bray, F., Ferlay, J., Pisani, P. (2005). Global center statistics, 2002. CA: A Cancer Journal for Clinicians, 55: 74-108.

Pisani, P., Parkin, D.M., Bray, F., Ferley, J. (1999). Estimates of the worldwide mortality from 25 cancers in 1990. Internal Journal of Cancer, 83: 870-3.

Watanabe, A., Wachi, T., Omi, H. et al. (2000). Granulocyte colony-stimulating factor-producing small-cell carcinoma of the uterine cervix report of a case. Diagonistic Cytopathiology, 23 : 269-274. 